\title{
Loophole ethics in sports
}

\section{Oyvind Kvalnes and Liv Hemmestad}

Ethical challenges in sports occur when the practitioners are caught between the will to win and the overall task of staying within the realm of acceptable values and virtues. One way to prepare for these challenges is to formulate comprehensive and specific rules of acceptable conduct. In this paper we will draw attention to one serious problem with such a rule-based approach. It may inadvertently encourage what we will call loophole ethics, an attitude where every action that is not explicitly defined as wrong, will be seen as a viable option. Detailed codes of conduct leave little room for personal judgement, and instead promote a loophole mentality. We argue that loophole ethics can be avoided by operating with only a limited set of general principles, thus leaving more space for personal judgement and wisdom.

Keywords: sports coaching, ethics, leadership, phronesis, loopholes

\section{Introduction}

International sport is an arena for fierce competition, ambition and rivalry. At the same time, the practitioners are expected to promote fundamental values and virtues in society. The ways in which we organize our moral commitments with regard to sports activities can have significant social effects. It therefore matters how and where we draw the ethical boundaries for the methods and practices that can be used to win and succeed. How and why should we maintain the standards of fair play in sports? This general question has been thoroughly investigated within sports philosophy (see Loland 2002; Simon 2003; Lumpkin 2009).

The preferred practical approach to ethics in many sports settings is to formulate a set of detailed rules to define the limits to what should and should not be done in order to perform well and win, covering as many of 
the relevant situations and choices as possible. The merit of the rule-based approach is that everybody can, in principle, know up front what is expected of them. The expectations have been put down on paper, and are there for all to see. Proponents of this approach have a tendency to overlook its pitfalls, however. Detailed rules signal that the ethical issues have been thought through, once and for all. All that remains is to live by the rules, consulting them whenever one is in doubt. In reality, however, each new situation can demand ethical reflection, based on the realization that the rules may be silent about the issue at hand. The silence is too often interpreted to mean that anything goes.

In this paper we will argue that a rule-based approach to ethics can encourage sport practitioners to adopt a loophole mentality that is likely to lead to more rather than less unethical behaviour in sport. We will also outline an alternative approach, based on Aristotelian ideas about practical wisdom. Our work is partly based on textual studies, and partly on our experience in facilitating ethical reflection among top coaches in various sports disciplines. What should a sports coach do when he or she faces circumstances in which a choice must be made between two or more alternatives that seem equally undesirable? In our dilemma training sessions, we have invited coaches to make decisions and justify them in the light of a simple set of ethical principles rather than a comprehensive set of ethical rules. Our experience from these sessions is that the coaches quickly adopt the principles in question, and seldom appeal to the ethical rules governing their field of conduct.

\section{The Sean Avery Rule}

The American ice hockey player Sean Avery is renowned for using the most cynical tactics to win matches for his team. His speciality is to tease and torment opponents behind the referee's back. He thus provokes violent retaliations, to which he himself remains passive, causing his opponents to be sent off. Throughout his career Avery has built up a reputation of being unsportsmanlike and a practitioner of unfair play. On 13 April 2008 he reached a new low point in that regard. During a match between his team, the New York Rangers, and their neighbours, the New Jersey Devils, he placed himself in front of Martin Brodeur, the opposing goaltender. With his back to the game, Avery stared at Brodeur and waved his stick and his hands in front of the goaltender's face, in an attempt to distract him and block his view. One of Avery's team mates came up to him and tried to push him away, unhappy with this attempt to give the Rangers team a better scoring chance. Avery continued until the attack broke down, went down the ice to participate in the preparation for another siege on goal, and in the 
following move actually put the puck in the net, scoring behind a deeply frustrated Brodeur.

Avery was able to defend his act of blocking the goaltender's view by claiming that he had not broken any rule by doing so - and he was right. Nowhere in the rules of ice hockey did it state that one is not allowed to distract the goaltender in the way he did. However, that was changed the day after the match. The ice hockey authorities made a swift response, by introducing a new rule. They released a statement to the effect that:

An unsportsmanlike conduct minor penalty will be interpreted and applied, effective immediately, to a situation when an offensive player positions himself facing the opposition goaltender and engages in actions such as waving his arms or stick in front of the goaltender's face, for the purpose of improperly interfering with and/or distracting the goaltender as opposed to positioning himself to try to make a play. (ESPN.com 2008)

With the new rule in place, any attempt to copy Avery and his method would be met with a penalty. It was soon baptized The Sean Avery Rule, after the man who provoked it to be put in place.

Avery's action and the response to it can be seen as an example of what we will call loophole ethics. It is a significant side-effect of a rule-oriented approach to ethics. This approach defines the boundaries of ethical behaviour in terms of rules or codes of conduct. The rules express the ethical standards expected of the members of a given community. When ethics is defined solely in terms of the rules that govern conduct, it can encourage a loophole mentality: if a particular course of action is not expressly defined as wrong, it is acceptable to perform it. Accordingly, the only thing a person needs to take into ethical consideration is whether the alternative he or she is contemplating is actually wrong according to the rules. Whatever action the rules do not mention, is acceptable. A person applies loophole ethics when they respond to ethical criticism by claiming that they have not broken any rules in doing whatever they have done.

Sean Avery's method of distracting the goaltender could not be sanctioned on 13 April, since he did not break a particular rule, but the situation changed on 14 April when a new rule was put in place. A loophole had been identified though Avery's action, and was then promptly removed. The nightmare for the ice hockey authorities is that there will be other loopholes, unfair and cynical alternatives which they have not yet thought about and eliminated by formulating a rule. By responding to Avery's action in the way that they did, they inadvertently provided further support for loophole ethics.

What is the alternative? Mick McGeough, an experienced ice hockey referee, claimed that he could and would have penalized Avery even without the new rule (Paumgarten 2008). In his eyes, what Avery did was unsportsmanlike conduct. A less experienced referee might have thought 
that he had no right to sanction Avery's distractions in the absence of a concrete rule. The ice hockey authorities also seemed to share this view, since they found it necessary to introduce a new rule. They could instead have supported the claim from the experienced referee, and agreed that even without a specific rule it was possible to sanction Avery's action. That way, they could have signalled that the participants in their sport - players, referees, coaches, and others - could not expect the rules to provide explicit answers in every case. Thus, each participating individual needs to make his or her own judgments about the choices faced and should not use as justification the absence of explicit rules stating that a given option is wrong.

\section{Loopholes and reward incentives}

Worries about the emergence of loophole ethics in sports belong under the heading of how a set of moral norms and ethical thinking provides incentives to the people who adhere to them. The philosopher Thomas Pogge has given a general account of the nature of loopholes in ethics, and his approach can help us to clarify the issue at hand. Its starting point is to acknowledge that the concrete ways we think about ethics can have good and bad effects, judged by the selfsame ethical standards. We can thus ask ourselves: 'Have we organized our moral commitments in a way that reflects, and helps effectively achieve, what by their own lights matter?' (Pogge 1992: 80). If the answer is negative, we have good reasons to take another look at the way we think about moral issues, and our ethical approach.

Fair play evidently matters in sports. There is a serious flaw in ethical thinking about sports if it provides incentives for unfair play. According to Pogge we cannot establish that it has such a flaw simply by showing that some individuals happen to be misguided into unfair play as a result of being exposed to our system of moral commitments. They may simply be foolish people who fail to grasp the incentives in a proper and reasonable manner. The relation between the code and the conduct must be tighter in order to establish that we are in the presence of a loophole:

\footnotetext{
A loophole only exists if the connection between the code and the regrettability of the conduct it encourages is tight in two respects. First, the relevant incentive must be an ideal one, so that the code can be said to guide agents towards the regrettable conduct. Second, the conduct must be regrettable in itself, rather than in virtue of any further effects it may bring about, however predictably. (Pogge 1992: 83-84)
}

Are these two criteria for loopholes met in the Sean Avery example? His conduct is surely an example of unfair play, and thus regrettable by the ethical standards of sports. It is regrettable in itself, so the second criterion is met. Yet is Avery guided towards the conduct by the code of conduct 
itself? Does it provide incentives to stand in front of the goaltender and distract him, or is this just the whims of a cynical individual?

We can reflect on these questions in the light of a distinction Pogge draws between two kinds of incentives: compliance incentives and reward incentives. With the former, the sole motivation to act in a particular way comes from the commitment to adhere to the code. When Avery distracts the goaltender, it is not an action motivated by a wish to adhere to the code of conduct within ice hockey. The code does not provide him with a compliance incentive to act that way.

What then with reward incentives? In Pogge's words (1992: 82), they are active when adherents to a code of conduct 'are motivated by other, codeindependent interests of theirs insofar as these can be pursued without violating requirements of the code. Here a code encourages conduct by affecting the official pay-offs: eligibility for benefits or liability to burdens'. Avery had a reward incentive to distract the goaltender. The interest to have one's team win is a standard interest of players, and Avery pursued this interest within the scope defined by the rules that were in place on 13 April. Distracting the goaltender was rewarded under those rules. The ice hockey authorities realized this, and moved quickly to remove the loophole.

The rule-based approach to ethics in sports is at risk of encouraging unfair play not due to its specific content, but through its form. When moral commitments are organized in comprehensive codes of conduct, people can be guided into thinking that all they need to do is to stay clear of any alternative that is clearly expressed as morally forbidden. They can thus be given reward incentives to act in ways that are regrettable and bad, even according to the ethical outlook that allows them to act in that manner.

We are not making a determinist claim here, to the effect that rules necessarily lead people to look for and exploit loopholes. It is rather the case that the rules can be interpreted in this manner, and may promote and encourage actions that even according to the rule-makers themselves are regrettable. One step to avoid such a development can be to rely less on detailed rules, and more on personal judgement and practical wisdom. This approach does not allow the agent to justify his or her actions simply by pointing to the fact that there are no rules explicitly defining their choice as wrong.

\section{Accounting}

A rule-based approach to ethics has a strong foothold in many parts of society. It is often seen as a solution to moral crisis. Let us make a detour to one area where this has been the case, to see how well the approach has fared there. This will put us in a better position to evaluate the possible merits of the same approach within sports. 
When the accounting business came under ethical scrutiny at the beginning of this century, as a result of the Enron scandal and similar cases, it was met with a general outcry for more detailed rules and regulations. None of the accountants who had taken part in the proceedings could be criticized for breaking any rules, although their working methods, particularly their close personal and economic ties to the people they were supposed to control, were seen as seriously flawed. How have accounting organizations and governments worldwide responded to the challenge? The answer is, by formulating more detailed ethical rules and regulations for accounting. The document Code of Ethics for Professional Accountants was at the beginning of this century a document consisting of 98 pages. In the recently revised version it has been expanded further. The main focus in the revision work was to identify loopholes and cover them up.

Critical voices within the finance sector are now claiming that the preferred rule-based approach may not only be insufficient as a response to ethical challenges, but may also make matters worse, by encouraging what we have labelled a loophole mentality. The critics recommend a shift from a rule-based to a principle-based approach (Somerville 2003). Guidance should be given through a limited set of general principles rather than through comprehensive and detailed rules. One advantage of such a move could be to limit the scope of what Pogge calls reward incentives. The agent's personal interests will remain intact, but he or she will now have a harder job defending and justifying a choice to pursue them in the light of the code's silence on the matter. A move away from comprehensive codes towards a limited set of general principles changes the logic of the justification requirement. This means that more personal reflections have to be invested in the process of justifying choice. It is not enough to scan the code in search of explicit mentions of the options available. In the last section of this paper we will present one way to bring ethical principles into the frame of reasoning about one's choices.

Internationally, sport faces a challenge similar to that of accounting: How do we avoid that people think and act as if any action that is not defined as wrong in the rules is acceptable? In accounting, the strategy of adding new rules to make the overall code more comprehensive has had the unfortunate side-effect that people act as if the relevant moral thinking has already been performed by the rule-makers. In sports, the tendency to rely on rules is not yet as strong as in the accounting sector. People within sports can look to accounting if they need a concrete scenario of what lies ahead if they take the rule-approach further, and continue in the pattern suggested by the authorities in The National Hockey League by expanding on the rules. They will then have further incentives to be on guard against a loophole mentality that otherwise threatens to undermine personal judgment. 


\section{Fair play}

The Hungarian soccer player Peter Kovacs was faced with a dilemma in a match between his team Odd Grenland and Brann Bergen in August 2009. The opposing goalkeeper Håkon Opdal injured a knee in an attempt to make a clearance. He fell to the ground in considerable pain. The ball fell to the feet of Kovacs. What would he do next? He could either roll the ball over the line and score, or he could kick the ball into touch, bringing play to a halt and provide the goalkeeper with the chance to receive medical treatment.

Kovacs decided to disregard the fact that the goalkeeper was incapacitated due to injury, and scored. Should he have stopped play instead of kicking the ball over the line? Was this an example of unfair play? In his own eyes, Kovacs had done nothing wrong, since the referee had not blown his whistle. After the incident he was quoted as saying: 'I can understand the frustration of my opponents, but I just follow the rules and play until the referee blows his whistle. I am a forward and want to score goals. This was an opportunity to do so' (TV2 Sporten).

Kovac's conduct and justification of his choice is typical of what we can expect in a rule-oriented environment. Nobody could disagree with the claim that he was not a rule-breaker. What other basis could there be for criticizing him? He had a reward incentive to score, since it was in his personal interest to score for his team and he could do so without violating any rule.

In his response to the incident, Kovacs failed to acknowledge the distinction between the formal and informal dimension of fair play (Loland 1998). Kovacs can reasonably claim that he did not break any formal rules. $\mathrm{He}$ is nevertheless vulnerable to criticism about the informal dimension of having broken the unwritten and implied agreement within sport of treating others with respect and dignity. In a rule-oriented environment the appeals to the unwritten aspects of fair play are subdued.

\section{Complexity and wisdom}

The moral landscape of sports is complex and ambiguous. It is impossible to navigate in it without friction. Athletes and their coaches face numerous dilemmas in their preparations to perform and win. How are they equipped to meet these difficult choices?

Performances in sports have been greatly enhanced by breakthroughs in physiological and nutritional science. We know increasingly more about how the human body works and the kinds of exercises that will improve its performance. This development has also encouraged a technological orientation in the approach to sports ethics and values. The rule-based approach to ethical issues can be seen as an attempt to make even the handling of 
dilemmas a technical matter. If one is face with a difficult choice, one can consult the code of conduct and follow its instructions.

This approach will in many cases lead to failure, since the subject matter of sports ethics in essence is dynamic, complex and ambiguous. Each new situation calls for the application of practical wisdom. Recent reflections on sports coaching have pointed to the Aristotelian tradition in general, and the concept of phronesis in particular, as a fruitful foundation for a methodical approach more in tune with the ethical challenges in sports (Hemmestad et al. in press; Standal \& Hemmestad 2010). This tradition highlights the need to develop prudence and practical wisdom through experiences in facing and handling difficult situations.

Phronesis is an intellectual virtue developed through social interaction, particularly with role models, rather than through theoretical study. According to Aristotle, it takes years to acquire it:

Whereas young people become accomplished in geometry and mathematics, and wise within these limits, prudent young people do not seem to be found. The reason is that prudence is concerned with particulars as well as universals, and particulars become known from experience, but a young person lacks experience, since some length of time is needed to produce it. (Aristotle 1934: 1142a)

Experience in dealing with particulars, then, is the only path to practical wisdom. One cannot read books or attend theoretical courses to acquire it.

In order to become autonomous and wise sports practitioners, athletes are dependent on the experienced people who guide them. A young athlete will thus look for moral guidance in more experienced athletes and in the coaches he or she encounters and works with. Being a role model is not something one can choose to whether or not to be. The up and coming people are the ones who will decide whether they want to regard someone as a role-model or not. Sports coaches should acknowledge that the athletes they coach will actually look up to them and take their moral lead from what they say and do in particular situations.

When Kovacs kicked the ball into an empty net and scored, his coach jumped with joy on the sideline, and afterwards made no attempt to correct the impression that he considered this a perfectly acceptable way of scoring a goal. Any coach facing such a situation could have used it as an opportunity to correct the player and his conduct. He or she cannot choose not to take a moral stand, and whatever he or she chooses to do will create a guideline for how such situations should be dealt with by players who encounter them later. 


\section{Two principles}

The Aristotelian approach can be integrated into the training and development of coaches. In recent years there have been attempts to do this by facilitating dilemma training with high-level sports coaches in Norway. We have confronted them with concrete dilemmas, situations where they must choose between two alternatives that can both be seen as the right thing to do. We have invited them to reflect on the cases at hand, not in the light of codes of conduct for sport, but rather from a stripped-down and simple conception of ethical argumentation.

The two principles we have presented to the coaches are firmly rooted in ethical tradition (see Kvalnes 2006):

The principle of equality:

Equal cases should be treated equally. A difference in treatment can only be justified by pointing to a morally relevant difference.

The principle of publicity:

One's choice should withstand public scrutiny. One should be ready to provide justification for it and defend it publicly.

We ask coaches to consider the dilemmas they may encounter in their jobs, and use the two principles to identify the alternative they would opt for, and provide a justification.

Both principles are formal rather than substantive. They can be applied by people with differing moral outlooks and values, and thus do not guarantee any uniformity in the answers and choices of the people who adopt them. They nevertheless provide a common foundation for ethical reflection. People who disagree on moral grounds can use the principles to identify the exact content of their disagreement.

The conclusion we draw from using these principles in practical settings, where coaches facing concrete dilemmas, is that they are well suited to sharpen the focus of dialogue about moral issues in sports. They provide guidelines for reflection on dilemmas and help people reach beyond the stage where they feel that a particular action is right or wrong. In the dilemma sessions soccer coaches have been trained to use the principles actively to identify the preferred course of action, and to provide justification for their choice. From what we have observed, the absence of more detailed and substantive codes of conduct has not been a source of frustration to the participants.

How well do the coaches fare when they return to the training ground after the dilemma sessions? Are they better equipped to deal with the everyday dilemmas of their profession? We cannot document that participation in dilemma training has improved their ability to handle the ethical challenges they face. Further study is needed in order to establish that 
dilemma training can lead to such improvement. The positive feedback from the participants in our own dilemma sessions nevertheless gives us reason to think that this approach can serve to strengthen their ethical awareness and the ability to reason about ethical choices.

\section{Conclusion}

Loophole ethics is a regrettable side-effect of a rule-based approach to ethics in sports. The conduct and reasoning of the ice hockey player Sean Avery and the soccer player Peter Kovacs can be seen as examples of a tendency to exploit loopholes in the codes of conduct. Since the codes in both cases were silent about the chosen options, the players considered those options to be acceptable. In order to avoid loophole mentality, we need to organize our moral commitments differently. We can do so by making a shift from comprehensive and detailed codes to a limited set of general principles. The latter approach signals that each individual is expected to take a personal stand on the particular issue at hand. Practitioners should not expect to have an ethics manual by their side, providing them with clues and answers about what is expected of them when they face difficult choices. Instead, they need to engage in ethical reflection, individually and with their fellow practitioners, guided by a simple set of concepts and principles.

In order to prepare coaches and athletes for the dilemmas they invariably will encounter in the quest to perform better and win competitions, more emphasis should be put on the significance of wisdom and practical reasoning. The ability to make sound decisions can only be learned through experience and training. Sports authorities should take this practical dimension into account when they define ethical frameworks and design learning programmes for the people involved in sports activities at every level.

\section{Acknowledgements}

This paper has greatly benefitted from suggestions and criticisms from Sigmund Loland, Bjørn Myskja, Thomas Pogge, and two anonymous referees. 


\section{Literature}

Aristotle. (1934) Nicomachean Ethics. Translation by H. Rackham. Harvard: Harvard University Press.

ESPN.com (14 April 2008) NHL amends unsportsmanlike conduct rule in response to Avery's antics. Downloaded from http://sports.espn.go.com/nhl/ playoffs2008/news/story?id=3 346729

Hemmestad, L.B., Jones, R. \& Standal, Ø.F. (in press) Phronetic social science: A means of better researching and analysing coaching? Sport, Education and Society.

Kvalnes, Ø. (2006) Se gorillaen! Etikk i arbeid. Oslo: Universitetsforlaget.

Loland, S. (2002) Fair Play in Sport. London: Routledge.

Loland, S. (1998) Fair play: Historical anachronism or topical ideal? In Ethics and Sport, eds. M.J. McNamee \& S.J. Parry. London: Routledge.

Lumpkin, A. (2009) Modern Sports Ethics: A Reference Handbook (Contemporary World Issues). Santa Barbara, CA: ABC-CLIO.

Paumgarten, N. (2008) Puckhead. The New Yorker, 28 April 2008.

Pogge, T.W. (1992) Loopholes in Moralities. The Journal of Philosophy 89 (2).

Simon, R.L. (2003) Fair Play: The Ethics of Sport. Boulder: Westview Press.

Somerville, L. (2003) Accounting Changes Boil Down to Principles vs. Rules. The Business Journal, 28 February 2003.

Standal, Ø.F. \& Hemmestad, L.B. (in press) Becoming a Good Coach: Coaching and Phronesis. In Coaching and Ethics, eds. C. Jones \& A. Hardman. London: Routledge. 